\title{
Rwanda's Energy Profile and Potential Renewable Energy Resources Mapping toward Sustainable Development Goals
}

\author{
E.Mudaheranwa,Ye-Obong Udoka and Liana Cipcigan \\ Centre for Integrated Renewable Energy Generation and Supply \\ Cardif University \\ Cardiff, UK \\ mudaheranwae@cardiff.ac.uk, udoakahyn1@cardiff.ac.uk and cipciganlm@cardiff.ac.uk
}

\begin{abstract}
EDPRS (Economic Development and Poverty Reduction) II is one among Rwanda's strategies to achieve the MDG (Millennium Goal Development). One of its top priorities, is to focus on Energy Sector as stated in the sustainable development goal number 7 which is "Affordable and clean energy" [7]. As reported in [?], the government of Rwanda has the target to increase the access to electricity from $42 \%$ to $100 \%$ by 2025 by promoting the use of Renewable energy. However, it is shown that the energy consumption is increasing at the rate of $6 \%$ while production increases at the less rate and this might be a big challenge in meeting the demand and therefore making the MDG target difficult to achieve.

This paper first discusses the current energy profile in Rwanda where it focuses on electrical energy status in order to evaluate the available power generation, transmission system and load growth for better future plan. The paper also continues to track the possible available and untapped renewable energy resources and outlines the credible Path-ways for Rwanda's future of energy in the next 30 years and beyond by considering how much energy we might need and where it could come from and hence, how possibly the the different Electrical energy generation technologies could share in an effective way to satisfy the demand.To identify how the country needs to integrate the most renewable energy generation in its energy system,the results show that in $\mathbf{2 0 5 0}$ fuel is free to be totally decommissioned which results in a remarkable drop in $\mathrm{CO} 2$ emission.
\end{abstract} tion

Index Terms-Development,Energy,EnergyPlan,Load, Simula-

\section{INTRODUCTION}

Researches have shown that Rwanda is well blessed with energy resources, such as solar, biomass, hydro, methane gas and geothermal as it was discussed in [7]. Unfortunately, most of these valuables remain untouched where it was reported in that resources for power generation totalling to about 1,200 MW of these energy sources have not been exploited [2], [8]. This is due to the fact that the wood is still the major source of energy where the total of about $90 \%$ per cent of the population use wood energy for their everyday life based activities and the imported petroleum products [2] Electricity is to be increasingly used as required by the Government in order to drive Rwanda's growth, but currently, it accounts for only $2 \%$ of all energy consumed. In contrary, biomass got going to $85 \%$ of all energy consumed,whereas the report [2] shows that $13 \%$ of the country's gross energy consumption is from petroleum. Having a look at the energy use image,it was found that the most of energy consumers are households $(82 \%)$, which predominantly use energy in the form of traditional fuels like wood. The second sector in using energy is the transportation $(8 \%)$ then industry $(6 \%)$, followed by the public services rating to (4\%) [8]

In the following section details on the status of energy sector in Rwanda ,covering its three sub sectors that include: electricity, biomass and petroleum are presented. In addition,Key data and challenges are delineated for better understanding of the perspective.

\section{ENERGY PROFILE AND BACKGROUND}

\section{A. Highlight on Rwanda's Electrical Energy Status}

1) Electrical Power Generation status: As of July 2018,the ministry of infrastructures in [2] has shown that the Installed capacity in Rwanda is at $218 \mathrm{MW}$, with an in country 212.5 MW and an import option of 5.5 MW. This capacity includes

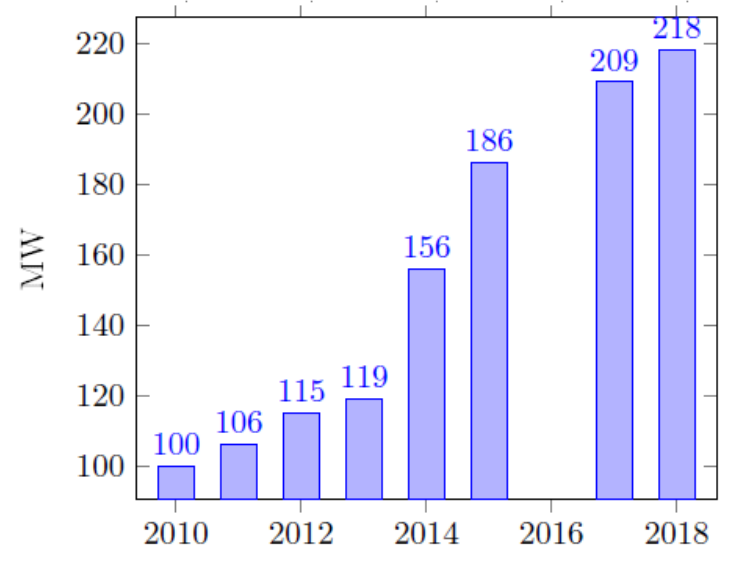

Fig. 1. Evolution in Installed Capacity

Hydro that makes around $45 \%$ of installed capacity, Diesel which goes to $27 \%$, methane gas $14 \%$, peat $7 \%$ and solar $6 \%$. 
This has been evolved to twice in 8 years since 2010, as it is presented on the graph in Fig.1 showing the evolution of installed electricity generation capacity in Rwanda since 2010. Since the operation of the hydro units is sometimes determined by the water level in the available and their mutual reliant, it impacts the power generation and the hydro availability goes down significantly during the sun season. In addition, the PV solar capacity is not constant, as its availability changes to low during the evening peak hours. Further, losses on the transmission and distribution lines (about $2 \%$ of the total installed power) [2] are to be considered. We can not leave behind that some of the units may be shut-down during certain periods due to maintenance or failure.This can lead to the fact that the total installed power of $218 \mathrm{MW}$ is not always available.

2) Power Transmission: As reference is made from the REG data presented in [9],the comment can be that the remarkable contribution has been made in construction and strengthening of transmission lines. This is due to the operations set up $744 \mathrm{~km}$ of high voltage (HV) transmission lines by the end of June 2017, from $371.4 \mathrm{~km}$ in 2007 .

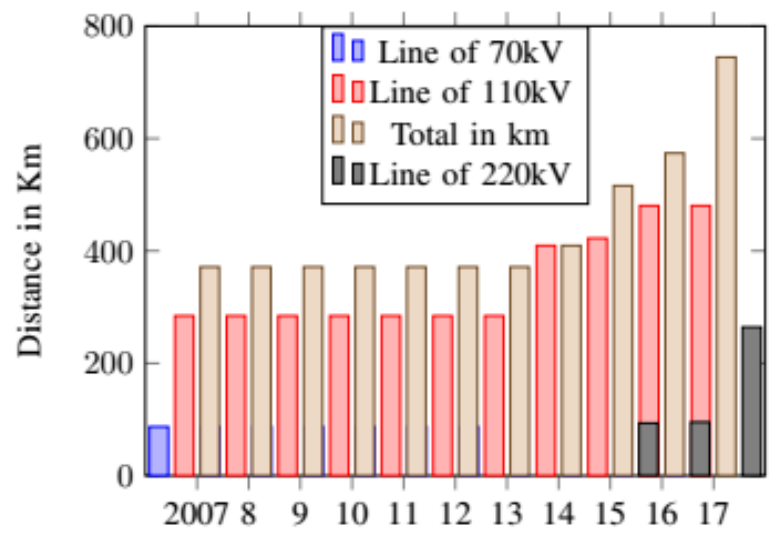

Fig. 2. Evolution of Power Transmission Line since 2007

The network is made of different transmission lines that pull power from various generation stations across the country, and at the same time making regional interconnectivity. Since July 2017, Rwanda transmission network is mainly a combination of $110 \mathrm{kV}(470.5)$ and $220 \mathrm{kV}$ transmission lines $(273.5 \mathrm{~km})$ as shown on the graph chart of Fig. 2 representing the evolution of Power Transmission Line since 2007

3) Present and projected Distribution network status: Hubs,substations, and antenna are the main subdivision of Rwanda distribution network Cumulatively, since about 2010, a total distribution network of at least 16,162 kilometres has been developed and built across the country, with the purpose extending electricity producers to the consumers where $5,590 \mathrm{~km}(35 \%)$ are Medium Voltage lines while 10,572 km $(65 \%)$ are low voltage distribution lines according to the data retrieved from [9]. Medium Voltage including $30 \mathrm{kV}, 15 \mathrm{kV}$, $17.32 \mathrm{kV}$ and $5.5 \mathrm{kV}$ lines cover the current Rwanda electricity distribution network. It was also estimated in the current electrification plan of Rwanda that, to achieve up to $100 \%$ electricity access by 2024, a total of $1016 \mathrm{Km}$ of MV lines will have been completed by then.

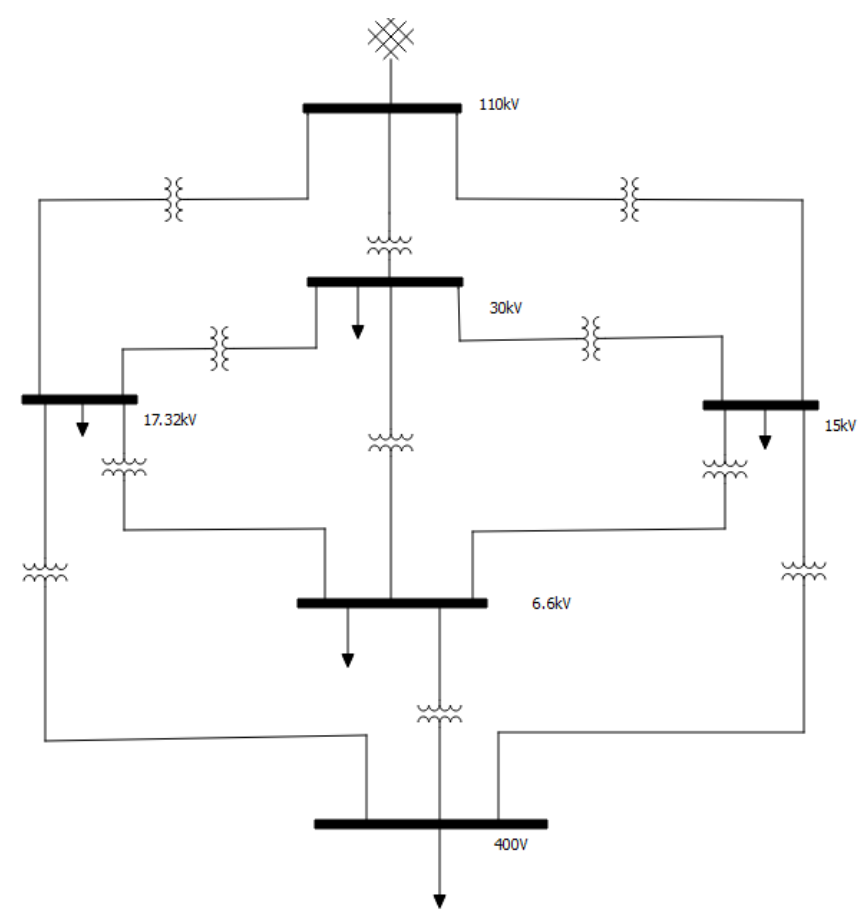

Fig. 3. Voltage profile for Rwanda's distribution network

The low voltage at which customers are connected is $400 \mathrm{~V}$ (three-phase, $230 \mathrm{~V}$ singlephase) and the network is currently,covered by $10,572 \mathrm{~km}$ of low voltage lines giving access to on-grid electricity access of $34 \%$ of Rwanda households.

4) Electricity access status: The bar chart in Fig.4 below shows a rapidly growing access to electricity as it has been pointed out in [9], where a growth has be been multiplied by 18 since 2006 passing from 77,181 in 200 to $1,384,958$ connections in 2018. This includes On-grid and off-grid connection

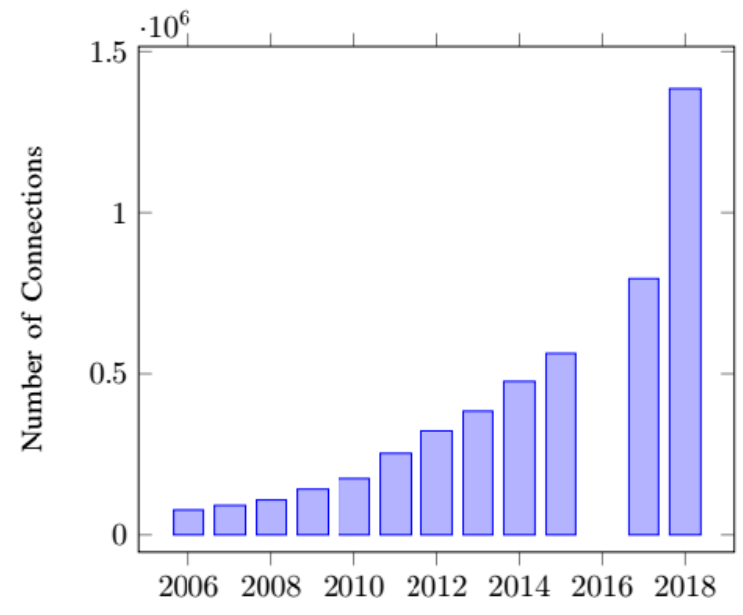

Fig. 4. Evolution in households connectivity

where Consumption of on-grid electricity is split between households, industry and the public sector. Households are the 
largest consumer category (51\%), with lighting the primary use the evolution to the electricity access can be understood buy having a look at the chart below showing the collectivity growth since 2006.

The industrial sector is the second largest consumer of electricity (42\%), with motor-drivers and lighting the main uses. Industrial consumption is dominated by a small number of major consumers which operate in cement manufacturing, mining, textiles and the agricultural sector (including tea estates). Public sector consumption of electricity $(7 \%)$ is mainly for powering public buildings, street lighting and water pumping.

Off-grid electricity access is now recognised as the primary means by which access will be expanded across Africa in the short-to-medium term. In Rwanda, the development of off-grid electricity has been one of the key achievements for the electricity subsector in recent years. Off-grid access for households has grown from around $0 \%$ to $11 \%$, with appropriately 300,000 households connected as of end June 2018 [2].

5) Energy Losses: Transmission and distribution losses in Rwanda as at June 2017 were 22\%, significantly higher than the international benchmark of $6 \%$ to $8 \%$. Of this total, $17 \%$ were technical losses and 5\% commercial. This was equivalent to $128 \mathrm{GWh}$ in lost energy, resulting in a financial cost of $\$ 28$ million. For comparison, total losses of $6 \%$ would have resulted in a financial cost of $\$ 8$ million [2].

\section{B. Potential Energy Resources Tracking toward the future}

Rwanda has a range of indigenous resources that complement each other in the energy mix.This section summarises the contribution of each of these resources. Table I summarizes the tracked power generation technologies that are estimated for Rwanda's energy demand satisfaction.

TABLE I

FUTURE POWER TRACKING

\begin{tabular}{|l||l|l|}
\hline \multicolumn{3}{|c|}{ Estimeted future energy genration Technology } \\
\hline Technology & Estimated quantity in MW & Constraints \\
\hline Hydro & 313 & Climate change \\
Methane & 350 & For 50 years \\
Solar & Available & 30MW identified \\
Peat & 267 & For 30-50 years \\
Geothermal & 300 & Not yet proven \\
Wastes & Proven & Low capacity \\
Biogas & not known & But availbe \\
\hline
\end{tabular}

1) Hydro Power: Studies suggest that topography of Rwanda is most suitable for medium to high head pico and micro hydro run of river schemes. Rwanda overall technical hydro-power potential has been estimated at up to $400 \mathrm{MW}$ although this varies by study. An assessment of the energy sector undertaken by the African Development Bank in 2013 estimated Rwanda domestic hydro-power potential at $313 \mathrm{MW}$, broken down into $130 \mathrm{MW}$ of domestic and $183 \mathrm{MW}$ of regional hydro resources .

A significant proportion of national hydro resources have been exploited by private developers as a result of the pro- motion of investment opportunities in power generation by Government. Government is now focusing on the exploitation of very small hydro resources to power local communities as mini-grids. Shown in Fig.5 are the possible off and On grid hydro-power plant that can be constructed to contribute to the current power generation.In the studies conducted in 2017 at Ndaba fall,the results for the second photo showed that a potential power of $127 \mathrm{~kW}$ could be available to make a mini-off gird that can supply power to the two villages Ryabisine and Rusebeya in Western province of Rwanda,Karongi Districk.Note that these two villages are located in a rural area which is very far from the national grid and it could be better if a mini-grid is constructed for them to be connect.

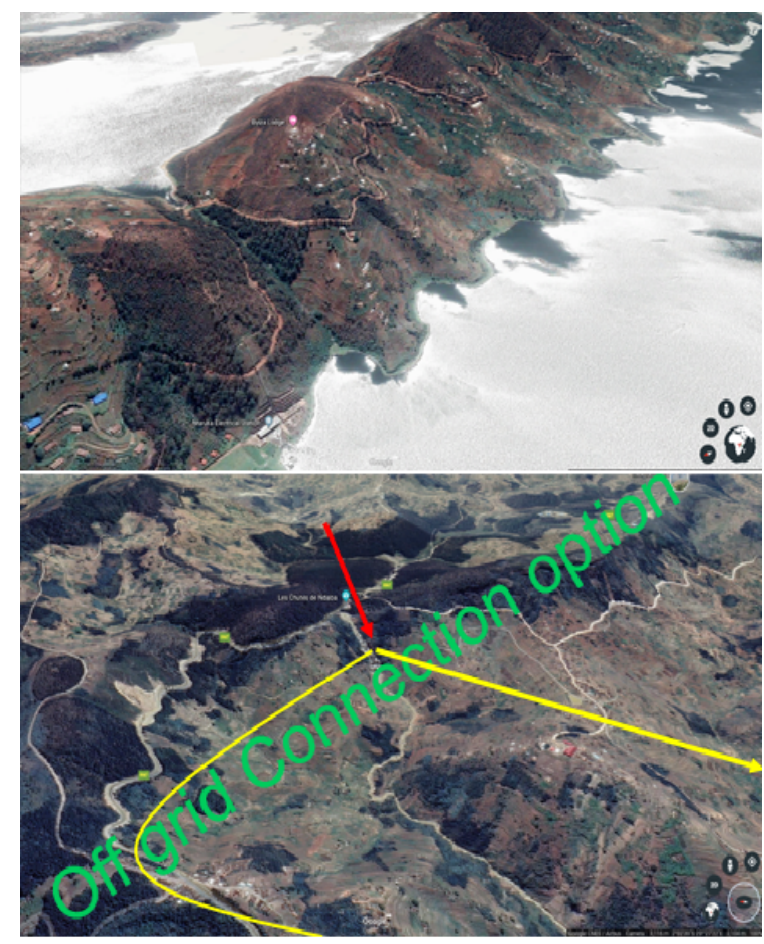

Fig. 5. Possible Hydropower resources for on and off grid

These are communities that would otherwise not be reached by the grid in the medium term. Regional hydro resources are also being developed. Rusumo Falls Hydro Power Plant is under construction and will supply power to Rwanda, Burundi and Tanzania, and Rusizi III and IV are in the pipeline, with power to be shared with DRC and Burundi.

2) Peat to power: A 2016 report concluded that from the 13,571 ha area studied, approximately 23 to 33 million dry tonnes of peat can be produced from an exploitable area of 4,057 ha. This peat can produce between 97 and 129 TWh for 30 years, at an estimated level of between 121 and $161 \mathrm{MW}$ [11].

3) Geothermal energy resources: Geothermal energy refers to the heat found within the earth. This can be harnessed by drilling into the ground and using steam to drive generators. Rwanda geothermal resource is yet to be proven. However, studies have identified Karisimbi, Kinigi, Gisenyi and 
Bugarama as promising areas, with potentially $47.3 \mathrm{MW}$ of generation available from five promising sites [12]. However, given the complexity involved in determining the commercial viability of geothermal power, much more detailed exploration studies and sub-surface drilling are required.

4) Solar energy: Rwanda solar radiation and solar resources have been assessed by the U.S. National Air and Space Agency (NASA) as well as the University of Rwanda and the study found that Rwanda Eastern Province has the greatest potential for generating energy from solar resources.

Another academic assessment, undertaken in partnership with the MININFRA Department of Meteorology in 2007, used a meteorological data set to estimate monthly averaged global solar radiation. This was found to vary between 4.3 and $5.2 \mathrm{kWh}$ per meter squared per day over all regions of Rwanda [13], [14]

It is planned that about 1.2 million households located far away from the national grid will be facilitated to access electricity through solar PV installations [2]. As for grid connected systems, two solar PV based power plants, one of $250 \mathrm{~kW}$ and the other of $8.5 \mathrm{MW}$, were connected to the national grid by the end of 2014 .

5) Methane Gas: The methane gas contained within Lake Kivu is Rwanda largest natural resource. The methane gas is the result of the globally unique geology of the lake and the naturally regenerating methane gas that is found there. Lake Kivu has 60-70 kilometre cube of Methane $(\mathrm{CH} 4)$ of which 44.7 kilometre cube can be extracted. There is a small annual accumulation of 0.14 kilometre cube per year. The amount of electricity that can be generated from this methane depends on the extraction. This efficiency is currently estimated at $28 \%$, lower than the 40 to $60 \%$ initially expected [16]. Therefore, initial forecasts of $700 \mathrm{MW}$ of generation for 50 years (to be split between Rwanda and DRC) have been revised downwards to $350 \mathrm{MW}$. Although it is currently anticipated that the primary end-use of the resource will be for electricity, methane gas has a variety of commercial and industrial uses. Further studies will be required to assess the potential of these [17].

6) Biomass: Small-scale power generation using agricultural residues (such as bagasse or rice husks) or biomass briquettes (from compacted waste residues or charcoal dust) is feasible at low levels of capacity. However,due to the lifestyle in urban areas, there are possibility to find considerable amounts of recyclable waste such as organic waste, paper, cardboard and wood that can be used to generate electricity [5].In 2012, for example, between 300 and 400 tons of solid waste were collected every day in Kigali City alone [6] and therefore,this should not be left behind in planning for future electricity supply.

\section{Methodology}

This section discusses the methods used to analyse the evolution of Rwanda's electricity supply based on the target for SDGS achieving to see the way the demand could be met by considering the integration of renewable energy resources. In summary,it discusses the estimated electricity demand and generation analysis and concludes with highlighting ways in which power generation and associated emissions are estimated.

\section{A. Electricity demand analysis}

This analysis of the electricity consumption is achieved after grouping the power demand into two sectors which are the residential and non-residential where residential sector is divided into households while the non-residential sector comprises together the agricultural, the industrial,and the service sectors.

To estimate the power demand in future,the power consumption per house in base year and the projected population altogether with the GDP are the factors that are required. The average power consumption per an electrified household for the base year (2012) is estimated using the Eq.(1)where $E_{A v}$ represents the average annual electricity consumption of an electrified household (in $\mathrm{kWh}$ ), $P_{i}$ is the rated power of appliance in a house $i$ (in $\mathrm{kW}$ ), $n_{i}$ is the average number of appliance $i$ per household, $h_{i}$ is the usage time of appliance $i$ (hour/day), and 365 is the number of days in a year. The data used in Eq. (1) were retrieved from the Fourth Population and Housing Census [3] , and from the Economic Data Collection and Demand Forecast.

study [1].

$$
E_{A v}=365 \times \sum_{i=1}^{n} P_{i} \times n_{i} \times h_{i} \times p_{e, i}
$$

As it is the policy of the Government to achieve the sustainable development goals, this study assumed $100 \%$ electrification to means that all households would be connected to the national grid in 2050. Therefore, it is only required to project the number of households that would be there in 2050 and it is estimated based on the population growth.

To estimate the population towards 2050, approaches used in three existing projection scenarios for the 2015-2050 period by the National Institute of Statistics Rwanda (NISR) are adopted. To estimate the evolution of the power consumption by the non-residential sector, the the past electricity consumption and the GDP of this sector are chosen and then the regression method of ordinary least squarest is adopted to determine their relationship using the Eq. 2

$$
y=a x+b
$$

where $y$ represents the non-residential sector's energy consumption and $x$ the sector's GDP.

The slope $a$ and intercept $b$ are determined using Eq.3 and Eq. 4

$$
a=\frac{n \times \sum_{i=1}^{n} x_{i} y_{i}-\sum_{i=1}^{n} x_{i} \sum_{i=1}^{n} y_{i}}{\sum_{i=1}^{n} x_{i}^{2}-\left(\sum_{i=1}^{n} x_{i}\right)^{2}}
$$

$b=\frac{n \times \sum_{i=1}^{n} x_{i}{ }^{2}-\sum_{i=1}^{n} y_{i}-\sum_{i=1}^{n} x_{i} \sum_{i=1}^{n} x_{i} y_{i}}{\sum_{i=1}^{n} x_{i}{ }^{2}-\left(\sum_{i=1}^{n} x_{i}\right)^{2}}$

Where $x_{i}$ is the total GDP for year $i$ while $y_{i}$ is the power consumed by the non-residential sector in producing the total 
GDP for year $i$. For the future power demand of this sector, three scenarios for electricity consumption were developed with the help of different GDP growth rates but for this study only the medium scenario is considered. As shown by the simulation results,it is estimated that by 2050 , the total annual power consumption turns around to $6,745 \mathrm{GWh}$ for the very low scenario, 8,210 GWh for the very likely scenario, and $10,450 \mathrm{GWh}$ for the very high scenario, compared to $380 \mathrm{GWh}$ in 2012

As for the power generation capacity requirements the Government plan for hydro-power generation is to have an increase in the installed capacity from $254 \mathrm{MW}$ by 2025 to the national estimated (energy policy) capacity of about 350 MW by 2050. Also, a power generation of about $350 \mathrm{MW}$ and $250 \mathrm{MW}$ for methane and geothermal-based are planned to increase up to their maximum estimated capacities as for the government policy by 2050 . However , as for the development in solar power generation the policy envisages $39.75 \mathrm{MW}$ by 2025 [8] and projected to a cumulative capacity of $100 \mathrm{MW}$ by 2050 .

Having a look at peat to power technology, a capacity of 250 MW is considered in the simulation. In the government energy strategic planning, it is assumed that the demand couldn't be met by the the mentioned power generation.However,the policy concludes that the technologies could be covered by the imported power and therefore the import/export capacity of $400 \mathrm{MW}$ is used in the simulation whereas the generation from imported fossil fuels is assumed to be decommissioned by 2050 .

\section{Simulation Discussion}

In this work the EnergyPLAN is used as a simulation tool and simulates the operation of national electrical energy systems on an hourly basis. The data to be considered are summarized in Table II below.

TABLE II

SIMULATION DATA

\begin{tabular}{|c|c|c|c|c|}
\hline \multicolumn{5}{|c|}{ Installed capacity per technology } \\
\hline & \multicolumn{2}{|c|}{2019} & \multicolumn{2}{|l|}{2050} \\
\hline Technology & MW & $\%$ & MW & $\%$ \\
\hline Hydro & 117.52 & 53.2 & 313 & 22.2 \\
\hline Methane & 28.5 & 12.9 & 350 & 24.8 \\
\hline Solar & 12.08 & 5.5 & 100 & 7.1 \\
\hline Peat & 15 & 6.8 & 250 & 17.7 \\
\hline Fuel & 30 & 13.6 & 0 & 0.0 \\
\hline Geohtermal & 0 & 0 & 43.3 & 3.6 \\
\hline Import & 18 & 8.1 & 400 & 28.3 \\
\hline TOTAL & 221.1 & 100 & 1456.3 & 100 \\
\hline \multicolumn{5}{|c|}{ Electrical energy demand } \\
\hline Year & \multicolumn{4}{|c|}{ Estimated quantity in GWh } \\
\hline 2019 & \multicolumn{4}{|c|}{778.3} \\
\hline 2050 & \multicolumn{4}{|l|}{8210} \\
\hline
\end{tabular}

The projected demand and supply are simulated to be compared with the current energy system in order to analyse the effectiveness of Rwanda future energy system.This work considers only the model of the year 2019 as the reference model and compares it with 2050 which is set to be the end year.It then in return proposes an effective way in which different technologies will contribute to the energy supply with a reduced emission at the optimum cost.

As for simulation results, Fig.6,the electricity production,demand and balance for the year 2019.
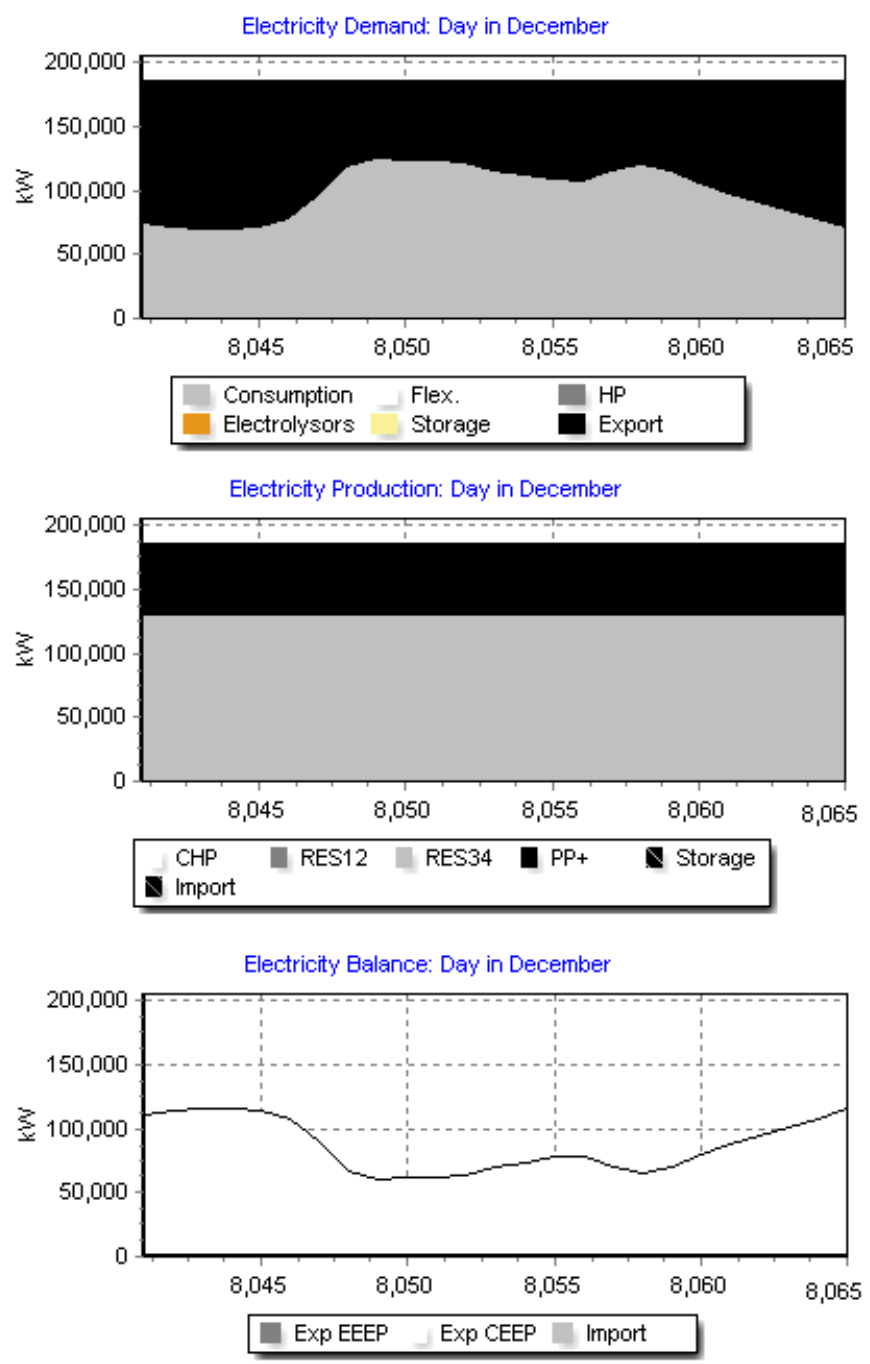

Fig. 6. Demand,generation and balance profile in 2019

It can be seen very well that about $45 \%$ of generated power is not used domestically where the graph shows that it can be exported to other countries. The simulation results also show an energy system with an emission of about 280 kilo tonne as indicated in Fig.7

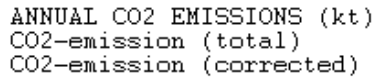

Fig. 7. Emission in 2019

When considering the demand in 2050, the additional parameters are added. This is because people mindset about energy usage is supposed to be changed and also introduction of some newer technologies is considered.These 
include:electric vehicles integration,Flexible Residential Demand,decentralization and other new policies that could be adopted by the government.The simulation results for proposed Rwanda's electrical energy supply and demand system energy are shown in Fig. 8 below The graphical representation
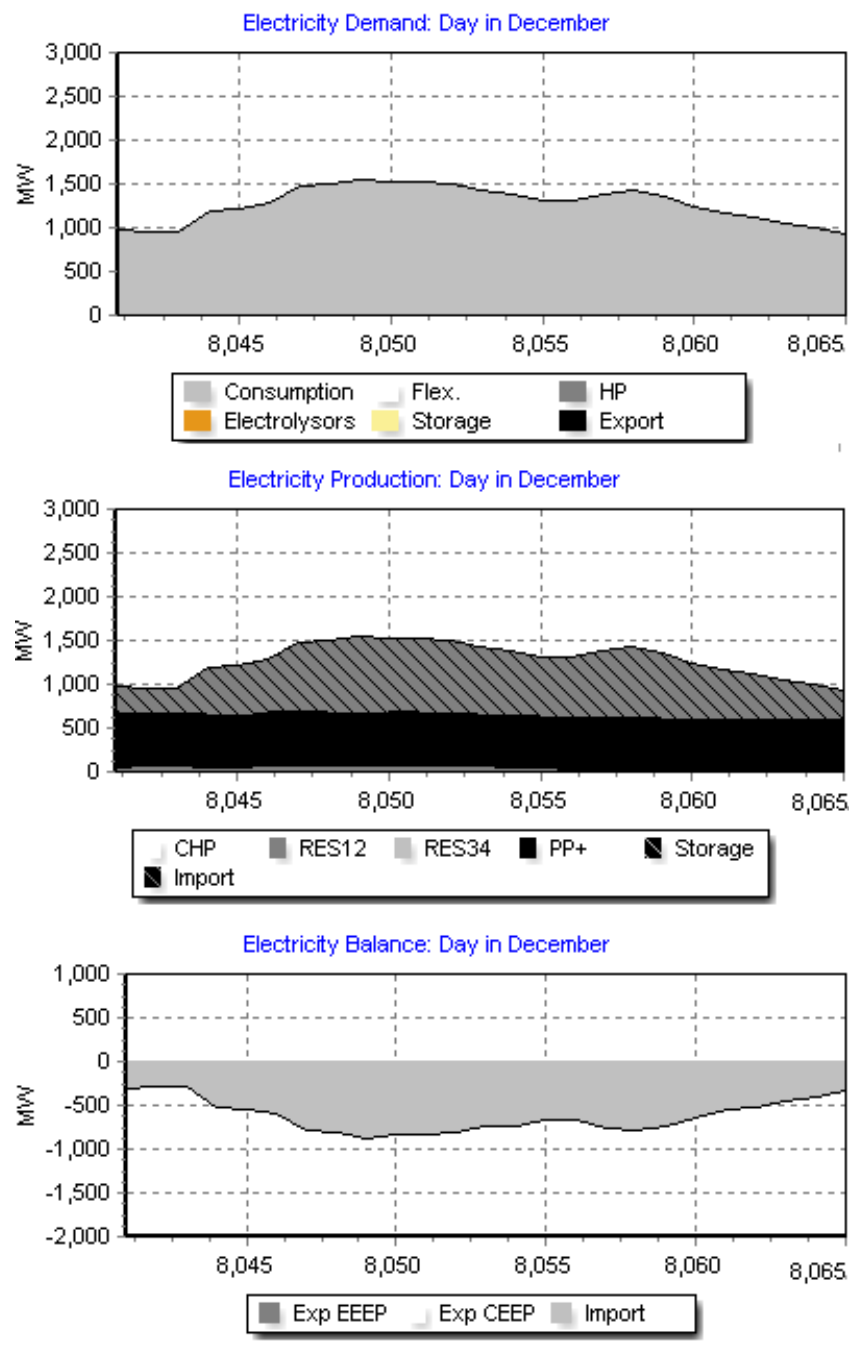

Fig. 8. Demand,generation and balance profile in 2050

on Fig.8 shows that in 2050 a peak power demand in a day could increase at around $1,500 \mathrm{MW}$ and this one is only for domestic, industrial, agriculture and transport consumption. It is very well seen that by this year no power available for export instead an an import of about 500MW will be needed and this requires an addition capacity of about 100MW in interconnection as shown on electricity balance curve.

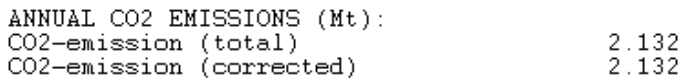

Fig. 9. Emission in 2050

As for electrical energy production and consumption emission, Fig. 9 shows that a reduction in $\mathrm{CO}_{2}$ footprint of about 750 kilo tonne is observed.

\section{CONCLUSiON}

Rwanda as a developing country is putting much effort to achieve its sustainable development goals. The paper highlighted the current electrical energy system status and assessed the future of the country energy system to analyse its effectiveness by considering the country's energy conservation strategies and policy.It is in this regard that the simulation results have shown the possibility of banning down the use of fuel while adopting the integration of renewable energy resources and increase in interconnection capacity.

The results show a decrease in $\mathrm{CO}_{2}$ emission from about 2.8 in 2019 to about 2.1 mega tonne in 2050 while considering an installed capacity of about 1,500 MW to supply a demand of 8.210 TWh when achieving the target of $100 \%$ electricity access.

The results have shown a very big difference in demand and supply either for the year of 2019 or 2050 but in opposite manner where in 2019 the country has the capacity of producing more power than what is consumed whereas in 2050 a very big quantity of power is to be imported as the demand has been proved to be much more that the installed capacity. It is in this angle that farther studies are suggested to analyse the possible flexibility either in residential,industry or agriculture demand for an optimum interconnectors capacity

\section{REFERENCES}

[1] Fichtner and decon. 2009. Economic Data Collection and Demand Forecast. Kigali: ELECTROGAZ.

[2] Minenfra,Energy Sector Strategic Plan(2018/19 to 2023/24),September 2018 ,

[3] National Institute of Statistics of Rwanda. 2013. Statistical Yearbook Rwanda 2013. Kigali: National Institute of Statistics of Rwanda. www.statistics.gov.rw/file/3140/download? token= TPQSGeLv

[4] Short, T. (2008). Sustainable development in Rwanda: Industry and government. Sustainable Development, 16(1), 56-69.

[5] AfDB. 2013. Rwanda Energy Sector Review and Action Plan. The African Development Bank Group (AfDB).

[6] City of Kigali. 2013. Terms of reference for waste to energy project in the City of Kigali.

[7] Safari B. A review of energy in Rwanda. Renewable and Sustainable Energy Reviews. 2010 Jan 1;14(1):524-9.

[8] Business-Sweden,OPPORTUNITIES WITHIN THE ENERGY SEC TOR IN RWANDA,November2016

[9] Rwanda Energy Group,Evolution of Power Transmission Network,November2018,

[10] Tumwebaze, Peterson. 2014. Rwanda to import 430MW of power to increase energy capacity. The New Times, Kigali, Rwanda

[11] Detailed study and assessment of peat bogs in Rwanda and their potential use as a source of fuel for power generation, (2016)

[12] The Project for Preparation of Electricity Development Plan for Sustainable Geothermal Energy Development in Rwanda, (2015)

[13] C. Museruka and A. Mutabazi, Assessment of Global Solar Radiation over Rwanda.Proceedings of the International Conference on Clean Electrical Power (ICCEP), 21 to 23 May, (2007)

[14] B. Safari and J. Gasore, 2009. Estimation of Global Solar Radiation in Rwanda Using Empirical Models. Asian Journal of Scientific Research, 2: 68-75.

[15] WJEC. 2015. World Energy Scenarios: Composing energy futures to 2050. World Energy Council (WEC).

[16] Wuest, A., Jarc, L., Burgmann, H., Pasche, N., Schmid, M. (2012). Methane formation and future extraction in Lake Kivu. In Lake Kivu (pp. 165-180). Springer, Dordrecht.

[17] Wuest, A., Jarc, L., Schmid, M. (2009). Modelling the reinjection of deep-water after methane extraction in Lake Kivu. EAWAG and BTC for the Governments of Rwanda and DR Congo, 141. 